EDITORIAL

\title{
Kudos to our Reviewers (Along with a Few Suggestions)
}

Can. J. Neurol. Sci. 2012; 39: 3

Happy 2012 ! At this time we would like to thank all the many people involved that it takes to make this journal possible. Your input is greatly appreciated! We hope it will be a great year for our readers.

A journal is only as good as its contents and we are pleased that the quality of papers published in The Canadian Journal of Neurological Sciences (CJNS) has been showing steady growth. We rely heavily on our reviewers to select and optimize the papers that we publish. Without exaggeration, your careful, expert analyses and constructive comments are the main determinants of our quality improvement. We cannot sufficiently express our gratitude to the legions of busy clinician-scientists who work anonymously, without financial or sufficient academic rewards*, for their diligent work for the Journal. We hope you will share our pride in the CJNS, which has been regarded as one of the most important products of The Canadian Neurological Sciences Federation (CNSF).

We would like to take this opportunity to offer some small points of advice to guide reviewers. These are meant only to further improve our timely and effective publication of articles and to avoid personal embarrassment and alienating or irritating our authors.

1. Commit when you can, but do not feel obliged to accept every invitation to review. We know you are busy and sometimes overwhelmed with responsibilities. When you do accept to do a review, please follow through and return the review in a timely manner. If you cannot do the review, it would be helpful if you would suggest an alternative reviewer or two.

2. In the comments to authors, give the impression that you have read and understood the paper. Occasionally reviewers make comments that indicate they have missed essential points or demand from the authors information that was already provided in the paper.

3. Provide an objective, evidence-based review and avoid making pejorative comments or overly criticizing the authors. We realize that sometimes papers are written badly and are difficult to review. Please be diplomatic in bringing these to the authors' attention. Avoid saying that the authors have ignored or neglected some information or failed to examine something or to provide a better statistical treatment, but provide constructive criticism and suggestions. These will be much better received and will help the authors produce a better paper.

4. It is fine to point out important articles that should have been cited or referred to, but avoid over-emphasizing your own publications. Give a balanced list if additional references are needed.
5. In the Comments to Authors, avoid overly praising or condemning the paper and please do not state whether the paper should be accepted or rejected.

6. In the Comments to the Editor avoid repeating what is said in Comments to Authors (the editor will read these, anyway.) Give your recommendation for acceptance, revision or rejection and the rationale for this decision in this section. You should comment on the significance and importance of the paper, which will help the editor decide on its priority within the issue in which the paper is published. Also comment on whether or not (and why) an accompanying editorial is indicated and please suggest an author or authors.

We hope these suggestions will help in your reviews. Good reviewers make good authors, and vice-versa; we hope that you will consider further aiding the Journal by submitting your own work to us.

Thank you, again, for your much-appreciated service.

G. Bryan Young
London Health Sciences Centre
London, Ontario, Canada
Cindy Leschyshyn
Canadian Journal of Neurological Sciences
Calgary, Alberta, Canada

* We should point out that there is a yearly Reviewer of the Year Award provided by the CNSF, presented at the annual meeting and that one can claim academic credit for reviews and also for being a member of our Editorial Review Board. 